DOI: $10.13037 /$ ci.vol20n43.5933

\title{
Redações jornalísticas em contexto de convergência: um estudo comparativo exploratório no Brasil, na Costa Rica e na Inglaterra
}

NEWSROOMS IN A CONTEXT OF CONVERGENCE: AN EX-COMPARATIVE STUDY IN BRAZIL, COSTA RICA AND ENGLAND

- Ébida Santos ${ }^{1}$

ORCID: https://orcid.org/0000-0002-7588-5822.

(Universidade de Brasília - UnB, Programa de Pós-Graduação em Comunicação e Sociedade, Distrito Federal, Brasil).

\section{Alexandre Lenzi ${ }^{2}$}

ORCID: http://orcid.org/0000-0003-3517-8434.

(Universidade do Sul de Santa Catarina - Uni-sul, Departamento de Comunicação, Tubarão - SC, Brasil).

\section{Benedito Medeiros ${ }^{3}$}

ORCID: http://orcid.org/0000-0001-9562-1587.

(Universidade de Brasília - UnB, Faculdade de Comunicação e Departamento de Ciências da Computação. Distrito Federal, Brasil).

\section{Gheorghita Ghinea ${ }^{4}$}

ORCID: http://orcid.org/0000-0003-2578-5580.

(University London, Department of Computer Science at Brunel. London, United Kingdom). 


\section{Resumo}

Este artigo faz um estudo comparativo exploratório para ajudar a compreender como redações jornalísticas no Brasil, na Costa Rica e na Inglaterra se relacionam com a convergência. A metodologia envolveu idas a campo e entrevistas, sintetizadas em quadros comparativos com base em dimensões propostas por Salaverría (2003) e subdimensões elaboradas pelos autores. À guisa da conclusão apresentamos um mapa mental de um modelo explicativo multinível de convergência, que demonstra como se dão os processos e as relações na produção jornalística.

\section{Abstract}

This article makes an exploratory comparative study to help understand how newsrooms relates to convergence in Brazil, Costa Rica and England. The methodology involves field trips and interviews, summarized in comparative tables based on the dimensions proposed by Salaverría (2003) and subdimensions elaborated by the authors. As a conclusion, we present a mental map of a multilevel explanatory model of convergence, which shows how processes and relations are produced in the journalistic production.

Palavras-chave: Jornalismo. Convergência. Keywords: Journalism. Convergence. Integration. Integração.

\section{Introdução}

Este artigo tem como objetivo descrever as dimensões e subdimensões da convergência nas redações jornalísticas dos jornais O Globo, do Brasil, La Nación, da Costa Rica, e BBC Television, da Inglaterra, diante do atual cenário de mudanças nas redações, devido a processos de convergência, integração e alterações na produção jornalística, de forma a construir um modelo explicativo multinível de convergência, como base nos depoimentos e preocupações dos seus profissionais. Após a realização de entrevistas abertas nos referidos jornais, em 2016 e 2017, elaboramos quadros classificatórios com dimensões e subdimensões que permitem comparar as redações e extrair informações de maneira mais organizada. Para a elaboração dos quadros utilizamos as dimensões-chave de Salaverría (2003), mesclando-as com subdimensões elaboradas por nós. A pesquisa limita-se ao compilamento dos dados fornecidos nas entrevistas realizadas e, por isso, existem lacunas informativas. Trata-se de uma pesquisa exploratória, de cunho descritivoteórico, embasada em entrevistas e na literatura da área.

Iniciamos a discussão pelo conceito de convergência e suas vertentes teóricas, tentando clarificá-lo para compreender em qual estágio de convergência e integração encontram-se as redações estudadas. Em seguida abordamos o jornalismo como negócio na era convergente, procurando discutir as implicações entre negócio e conteúdo jornalístico. 
A metodologia é detalhada na terceira parte do texto, quando explicamos as dimensões e subdimensões, para, em seguida, apresentar os quadros comparativos. Na quarta parte apresentamos a discussão dos resultados e em seguida concluímos, apresentando o modelo explicativo multinível de convergência gerado a partir das evidências da pesquisa.

\section{A convergência no jornalismo}

O conceito de convergência pode ser aplicado a diversas áreas do conhecimento. Nesta pesquisa, relaciona-se com o jornalismo e com as transformações pelas quais o sistema de produção de notícias tem passado nas últimas duas décadas, especialmente. O conceito de convergência midiática, desenvolvido por Henry Jenkins (2009) objetivou definir a tendência a qual os meios aderiram para se adaptar à internet e assim distribuir seus produtos. $\mathrm{O}$ conceito surge atrelado e motivado pelas mudanças tecnológicas e pela digitalização dos processos. A convergência funciona, portanto, como uma resposta aos novos processos comunicacionais surgidos com as Tecnologias da Informação e da Comunicação (TIC) e passa a afetar diversas dimensões da produção informativa (SILVA; RIBEIRO, 2013, p. 50).

Áviles et al. (2009, p. 175) afirmam que o termo convergência faz alusão à difusão das fronteiras entre as comunicações móveis e fixas. E no contexto jornalístico aplicase "aos desenvolvimentos tecnológicos, tais como a integração do vídeo na internet, o trabalho de marketing para a promoção conjunta de distintos meios associados e fusões de empresas de comunicação". Para Salaverría e Negredo a convergência viabiliza "uma integração de ferramentas, espaços de trabalho e linguagens anteriormente desagregadas, de forma que os jornalistas elaboram conteúdos que se distribuem através de múltiplas plataformas, mediante as linguagens próprias de cada uma"6 $(2008$, p.45).

Note-se que a integração das redações, uma das etapas essenciais da convergência, não se sobrepõe a ela, pois uma redação integrada, fisicamente, não é necessariamente convergente. "[...] os processos de reorganização que sacodem as redações de todo o mundo são apenas a espuma superficial de um fluxo muito mais profundo, o da convergência

\footnotetext{
${ }^{5}$ No original: "a los desarrollos tecnológicos, tales como la integración del vídeo en internet, el trabajo de marketing para la promoción conjunta de distintos medios asociados y fusiones de empresas de comunicación"

${ }^{6}$ No original: "una integración de herramientas, espacios, métodos de trabajo y lenguajes anteriormente disgregados, de forma que los periodistas elaboran contenidos que se distribuyen a través de múltiples plataformas, mediante los lenguajes propios de cada una".
} 
[...]"” (NEGREDO; SALAVERRÍA, 2008, p. 16). Assim, limitar a convergência à fusão das redações sem que, no entanto, ocorram outras mudanças estruturais é um erro grave, pois isso serve somente para reduzir custos a curto prazo e aumentar a produtividade, por mais que pretenda-se apresentar o processo de outra forma. Negredo e Salaverría (2008) explicam as diferenças: a convergência trata de um processo dinâmico, algo, por sua própria natureza, sempre inacabado. Exemplificam lembrando que duas linhas são convergentes quando se dirigem a um ponto de interseção. No entanto, quando estas mesmas linhas se unem, deixam de ser convergentes. E no preciso ponto onde ocorre esta interseção se situa a integração, entendida como a junção de duas ou mais unidades ou fluxos em um só.

Assim, a convergência, em seu sentido mais amplo, é vista como inevitável para qualquer grupo jornalístico. Enquanto a integração é uma das possibilidades. E depende de cada grupo empresarial decidir até que grau de convergência querem fazer chegar suas distintas unidades de produção. "De qualquer forma, o fundamental é ter em mente que convergência e integração não são a mesma coisa. A primeira palavra se refere a um processo; a segunda, a um de seus possíveis resultados. A convergência é inevitável. A integração, não"s (NEGREDO; SALAVERRÍA, 2008, p. 52).

Salaverría (2003) propôs, anteriormente, quatro dimensões articuladas entre si e que ajudam a classificar e compreender o processo de convergência midiática. A primeira dimensão é a Empresarial, que corresponde a um nível mais geral a partir de empresas que vivenciaram momentos de diversificação em termos de mídia. "Esta dimensão compreende o estudo das dinâmicas de multiplicação de meios no seio de um grupo de comunicação, assim como os modos em que esses meios se coordenam entre o econômico e o editorial"9 (SALAVERRÍA, 2003, p. 32). O desafio, segundo o autor, é passar da simples integração gerencial para a integração editorial dos diversos meios que compõem determinado conglomerado midiático. A segunda dimensão é a Tecnológica, que responde a evolução dos processos de produção e difusão pela imprensa e que trouxe "consigo uma reconfiguração profunda das tarefas jornalísticas e tem aberto novos horizontes

\footnotetext{
${ }^{7}$ No original: "los procesos de reorganización que sacuden las salas de redacción de todo el mundo son apenas la espuma superficial de una corriente mucho más profunda, la de la convergencia".

${ }^{8}$ No original: "En cualquier caso, lo fundamental es recordar que convergencia e integración no son la misma cosa. La primera palabra se refiere a un proceso; la segunda, a uno de sus posibles resultados. La convergencia es inevitable. La integración, no".

${ }^{9}$ No original: "Esta dimensión comprende el estudio de las dinámicas de multiplicación de medios en el seno de un grupo de comunicación, así como los modos enlos que esos medios se coordinan entre sí en lo económico y enlo editorial".
} 
ao jornalismo ${ }^{10 "}$ (idem, p. 33). Nesta dimensão se incutem os jornais eletrônicos ou digitais, responsáveis pelas maiores revoluções no modo de produção da notícia e que tem como desafio a implantação de sistemas integrados de gerenciamento de conteúdo e a transparência e fluidez no acesso por todas as mídias da empresa. A terceira dimensão é a Profissional, afetada profundamente pelos processos de convergência multimídia. Como explica Salaverría $(2003$, p. 33) "agora é preciso trabalhar mais depressa [...] conhecer novas técnicas de investigação para o uso das fontes digitais e dominar os códigos tanto textuais como audiovisuais para a elaboração de conteúdo multimídia"11. Portanto, os conhecimentos tradicionais já não bastam para se produzir jornalismo. Faz-se necessário ser um jornalista capaz de assumir múltiplas etapas do processo de produção. Neste caso, o desafio para a empresa é viabilizar capacitação e formação de seus profissionais diante do novo cenário.

A quarta dimensão é a Comunicativa. Nela são observadas as novas possibilidades da linguagem jornalística, que propicia uma nova retórica, com outras formas de contar a mesma história, entre elas a união dos formatos das mídias tradicionais - impresso, rádio e televisão - em um único espaço, o digital. O desafio é "pensar como se pode conseguir o máximo aproveitamento informativo das coberturas multimídia"12(p. 36).

A combinação dessas dimensões na prática do jornalismo relaciona-se com outro conceito de Salaverría (2014), sobre a multimídia. Para o autor, três aspectos são centrais para compreender o conceito: "1) como multiplataforma, 2) como polivalência e 3) como combinação de linguagens". No caso da multiplataforma ocorre a coordenação logística de distintos meios de comunicação; com a polivalência pode-se observar o perfil do jornalista, agora caracterizado pelo acúmulo de tarefas desempenhadas anteriormente por diferentes profissionais; e a combinação de linguagens ou formatos, mais usualmente relacionada a texto, som imagem e vídeo, e caracterizada pelos meios que as mídias utilizam nas transmissões de informação.

O jornalismo, especificamente, vem sendo fortemente afetado pelas mudanças no cenário tecnológico desde, pelo menos, os anos 2000. Trabalho organizado por Xosé López García e Xosé Pereira Fariña (2010) resgata que as iniciativas mais ambiciosas de integração de redações aparecem a partir de 2007, quando o inglês The Daily Telegraph dá

\footnotetext{
${ }^{10}$ No original: "consigo una reconfiguración profunda de las tareas periodísticas y ha abierto nuevos horizontes al periodismo"

${ }^{11}$ No original: "ahora es preciso trabajar más deprisa [...], conocer nuevas técnicas de investigación para el uso de las fuentes digitales, y dominar los códigos tanto textuales como audiovisuales para la elaboración de contenidos multimedia".

${ }^{12}$ No original: "pensar en cómo se puede conseguir el máximo aprovechamiento informativo de las coberturas multimedia"
} 
início a um processo que seria referência para reformas similares em jornais concorrentes. Em 2008, se multiplicam as iniciativas, cada uma com suas peculiaridades: Guardian Media Group, Financial Times, The Times, The New York Times, El Mundo, O Estado de S. Paulo, Clarín e El Tiempo de Bogotá são alguns dos exemplos.

No contexto atual é possível identificar iniciativas de convergência nas redações, nas formas de produção e no conteúdo. As mudanças nas rotinas das redações é um movimento inevitável nas dinâmicas que procuram implementar a convergência não só de conteúdo mas também de processos. Entretanto, o contexto multifacetado da convergência impede uma definição unanime de convergência - como defendem posteriormente autores como Avilés, Kaltenbrunner e Meier (2014) ao revisitar o conceito. Para os autores, a convergência aparece como um fenômeno que influencia o sistema de mídia, moldando diferentes dimensões da comunicação.

Ao estudar exemplos de interação de redações na Áustria, na Espanha e na Alemanha, Avilés et al. (2009 e 2014) apresentam três modelos de convergência de redações. O primeiro é o da integração plena, no qual a infraestrutura para produção multiplataforma concentra-se em uma única redação, controlada por um sistema central de notícias e de gestão do fluxo informativo. Nesta plena integração, os jornalistas deveriam receber formação para se adaptar à produção multimídia, ressaltam os autores. O segundo modelo é o da colaboração entre redações, em que os jornalistas trabalham em seções e redações diferentes, mas estão conectados por meio dos seus coordenadores multimídia ou de certas rotinas colaborativas ao longo do fluxo informativo. Neste modelo existe um intercâmbio de conteúdos e uma comunicação constante entre as equipes responsáveis pelos diferentes suportes, contudo, não há necessariamente uma integração da redação. Por último, é apresentado o modelo de coordenação de suportes isolados. Neste caso, não há uma organização da integração no fluxo de trabalho. Existe apenas uma colaboração voluntária de cada jornalista no processo de elaboração das notícias. García Avilés et al. (2009), no entanto, ressaltam que estes modelos não existem de forma pura e que, em uma mesma empresa, podem-se encontrar exemplos de cada proposta.

$\mathrm{O}$ aspecto tecnológico da convergência implica o proposto por Jenkins, de que cada dispositivo conectado a rede de internet pode interagir com conteúdos diversos, levando a processos transmídia. Trata-se de um percurso que impõe desafios ao jornalismo contemporâneo, entre os quais estão as negociações com novos atores (CANAVILHAS et al. 2016), as mudanças de contextos e de linguagens e a evolução de procedimentos (SALAVERIA; NEGREDO, 2008). Esses elementos acabam influenciando na cultura 
profissional dos jornalistas e consequentemente impactam nas rotinas e produtos. Considerar a notícia como "um produto institucional, moldado pelos imperativos das organizações de notícias” (MEIKLE, 2009, p.18) significa respeitar também a influência cultural - evento, lugar, normas e valores culturais - fundamental para compreender o que os profissionais pensam e como veem os novos processos pelos quais estão passando.

Thomas Hanitzsch (2007, p. 369) explica que, em relação às etapas de produção da notícia, as culturas do jornalismo são articuladas em três níveis básicos de análise: o nível cognitivo, em que "moldam a estrutura fundamental com base na qual a percepção e a interpretação de notícias e o trabalho noticioso aparecem"; o nível de avaliação, em que "dirigem as visões mundiais profissionais dos jornalistas, bem como ideologias ocupacionais; e o nível performativo, em que "se materializam" na forma como os jornalistas fazem o seu trabalho. Hanitzsch enfatiza que as práticas jornalísticas são moldadas pelas estruturas cognitivas e avaliativas, e os jornalistas, ainda que de forma inconsciente, perpetuam essas estruturas, que são profundas, em seu trabalho profissional.

\section{O negócio jornalismo na era convergente}

A habilidade das empresas jornalísticas para navegarem pelas mudanças tecnológicas têm consequências também sobre o modo como o conteúdo será produzido e comercializado. Por trás do noticiário, a expectativa em torno do retorno financeiro e o planejamento para a captação de audiências e para a modernização tecnológica preocupam os gestores e se tornam elementos fundamentais para a sobrevivência dos jornais. Entre incertezas do mercado, um fato merece ser destacado: desde 2014, na média mundial, a circulação já responde por uma fatia maior das finanças do que a propaganda, mostra pesquisa da Associação Mundial de Jornais e Editores de Notícias (WAN-IFRA - sigla em inglês) ${ }^{13}$. O estudo internacional, com dados referentes a 2014, revela que, em um resultado inédito, a circulação já era a principal fonte de receita para os jornais em 2014, ultrapassando a publicidade. Da renda estimada de US\$ 179 bilhões que as publicações movimentaram em 2014, US\$ 92 bilhões (51,4\%) vieram da circulação impressa e digital, enquanto US\$ 87 bilhões $(48,6 \%)$ da publicidade.

As questões financeiras são ainda motivo de conflito entre o jornalismo e o gerenciamento do negócio. Elena Raviola (2012) aponta três questões principais que

${ }^{13}$ World Press Trends: Newspaper Revenues Shift To New Sources. Disponível em: <http://www.wan-ifra. org/press-releases/2015/06/01/world-press-trends-newspaper-revenues-shift-to-new-sources $>$. Acesso em: 10 dez. 2018. 
emergem desse cenário: as mudanças nas práticas jornalísticas; as implicações para a identidade profissional; e as consequências organizacionais da coexistência de velhas e novas mídias.

A alteração da estrutura física do jornal, assim como a reconfiguração no âmbito da produção da informação, são comuns ao processo de convergência, que podem resultar ou não em integração das redações, das plataformas e dos conteúdos (SOUSA, 2013). Fazer jornalismo convergente requer investimentos financeiros em tecnologias, plataformas e estruturas físicas que facilitem o diálogo e a capacitação de pessoal. Em um cenário tecnológico de mudanças cada vez mais velozes, o jornalismo como modelo de negócio ainda dá passos no escuro e precisa fazer apostas incertas. Não se pode negar a crise nos suportes tradicionais do jornalismo, como o papel, e também nos modelos de negócio (SOUZA, 2017). A explosão da internet como espaço noticioso, e a sua confirmação como o principal espaço de troca de informações da atualidade, exigiu a organização das empresas de mídia em novos "modelos de negócio"14. A tentativa de se enquadrar nos novos modelos e de consolidar as empresas integra o rol dos desafios.

O novo contexto gera um movimento no qual marcas de jornais impressos passam a priorizar a produção de conteúdo online, apontado por Lenzi (2018) como um processo de inversão de papel, quando ocorrem mudanças de mentalidade, de comportamento e de ação prática no fazer jornalismo. Tal priorização da produção de conteúdo informativo para as plataformas digitais em redações com um fluxo de trabalho até então regrado pelo ritmo do impresso é apontada como um novo e necessário ciclo de inovação em empresas jornalísticas.

Ainda longe de um modelo de convergência livre de críticas, Lenzi (2018) aponta que tem ganhado força no contexto contemporâneo internacional a prática da coleta e formatação do conteúdo jornalístico feita por um mesmo grupo profissional integrado, enquanto o empacotamento do mesmo conteúdo é realizado de acordo com cada plataforma, ou seja, o trabalho de edição em si ainda é executado por equipes profissionais distintas.

Dentro dos desafios comerciais, a forma também se evidencia. O texto jornalístico vive em constante transformação, acompanhando as diferentes mudanças tecnológicas, sociais e culturais. A partir de Jorge, podemos dizer que a nova roupagem das notícias na era da convergência "é dada pelos sistemas de hipermídia, o hipertexto vindo em primeiro plano como ferramenta importante para a adequação da notícia ao espaço virtual" (2007, p. 11). As mídias passaram a conviver e, agora, jornal online, jornal impresso, tv e rádio

${ }^{14}$ Nesse sentido, trazemos a definição de "modelos de negócios" adotada por Souza (2017), que envolve a forma como determinado meio consegue recursos para executar suas atividades. 
se adaptam às novidades tecnológicas. Ao contrário do que era inicialmente profetizado, as formas anteriores, até o momento, não morreram. Nesse sentido Jorge entende "que elas estão mutando". Com isso, surgem fenômenos concomitantes: "as fronteiras ficam fluidas; os formatos sofrem alterações para se adaptar ao novo meio; há mudanças no modo de fazer; na concepção ética e estética dos novos produtos e na cultura organizacional" (JORGE, 2007, p. 298).

Com pesquisa que envolveu empresas na Alemanha, Holanda, Suíça, Áustria, Espanha e Portugal, Manuel Menke et al. (2016) apontam que ainda existe uma "cultura do impresso" dominante nas redações da Europa. Os autores entendem que este processo ainda está em sua infância e em ritmo lento, "porque a mudança no jornalismo é muito mais do que simplesmente a implementação de novas práticas" (idem, p. 1) ${ }^{15}$. Defendem, ainda, a compreensão do processo de convergência não apenas como uma forma de produzir e distribuir notícias, mas sim como resultado de uma reconfiguração cultural das redações com base em estratégias para a implementação de uma nova rotina. Neste novo contexto, por exemplo, vídeos, áudios e gráficos devem ser produzidos especificamente para os canais digitais e não mais trabalhados como subprodutos do impresso.

Menke et al. (2016) entendem que a convergência não é um fenômeno em seu estado final ideal e que uma formação adicional é vista como um elemento essencial para a implementação da cultura da convergência. E, apesar de reconhecerem que muitas vezes jornalistas podem ser bastante resistentes à mudança, indicam uma sensação geral de otimismo quando os profissionais são incentivados a se envolverem com novas tecnologias e novos formatos, o que pede uma nova postura dos gestores das redações. “O desafio da digitalização não é apenas substituir uma velha estratégia por outra nova, mas transformar um ramo de produção tradicional e estagnado em um modelo flexível e inovador" (MENKE et al., 2016, p. 19) ${ }^{16}$.

Exemplo prático pode ser observado no estudo de Belochio (2012) sobre o jornal Zero Hora, do Rio Grande do Sul. Ao pesquisar as implicações da convergência jornalística nas estratégias desenvolvidas por organizações noticiosas contemporâneas, constata que, no caso de Zero Hora, apesar de existir a intenção de uniformizar as referências sobre a marca, as características visualizadas nas suas várias publicações indicam que tal objetivo está sendo ultrapassado e que as inovações estão acontecendo. Ela faz distinções entre a versão em papel, o webjornal e ainda o jornal mobile em relação às implicações ao

\footnotetext{
${ }^{15}$ No original: "[...] because change in journalism is much more than simply implementing new practices". ${ }^{16}$ No original: "The challenge of digitization is not only to replace an old strategy with a new one, but to transform a traditional, stagnant production branch into a flexible, innovation-friendly one".
} 
conteúdo. Para Belochio, considera-se o webjornal como um dispositivo de encenação diferente do jornal impresso e dos jornais mobile. O jornal mobile estaria em meio aos impresso e o webjornal, sendo um misto dos dois, mantendo algumas particularidades. Tais adaptações demonstram um processo de transição que pode levar à sua transformação em outros dispositivos de encenação.

Somam-se às mudanças textuais a constante participação do público e a relação com a audiência, intensificada pelas redes sociais. Superada a ideia hipodérmica de um leitor receptivo, presenciamos a perspectiva do leitor produtor de conteúdo: a audiência participativa (TÁRCIA, 2007). Essa atuação dos leitores impacta a rotina produtiva dos profissionais e requer estratégias das empresas para lidar com demandas e sugestões do público. Essas estratégias envolvem tanto ações tecnológicas, como a criação de plataformas de interação, quanto definições de políticas editoriais sobre a adoção de conteúdos advindos da audiência.

\section{Estratégias metodológicas}

A pesquisa foi realizada a partir de dados empíricos coletados por meio de entrevistas abertas e não estruturadas realizadas com editores, designers e profissionais de tecnologia da informação (TI) de 2014 a 2017 nas seguintes redações: jornal O Globo, do Brasil; jornal La Nación, da Costa Rica; e BBC Television, da Inglaterra. Faz-se importante ressaltar que se trabalha com redações de dois jornais impressos e uma redação de televisão, que produz conteúdo para mídias digitais. Eles serão por vezes referidos somente como O Globo, La Nación e BBC ao longo do texto, estando implicito que dizem respeito às redações de tais veículos. As entrevistas que compõem o corpus desta pesquisa foram realizadas no âmbito do projeto Mídia Digital Multimodal, financiado pela Coordenação de Aperfeiçoamento de Pessoal de Nível Superior (Capes), fundação vinculada ao Ministério da Educação do Brasil. Em uma primeira etapa realizamos a audição e notação das entrevistas para a categorização das preocupações mencionadas pelos entrevistados. A partir das reflexões teóricas, organizamos quatro quadros classificatórios, com o objetivo de tornar visíveis os elementos da convergência presentes em cada jornal e de ordenar didaticamente as informações. Partimos inicialmente das dimensões propostas por Salaverría (2003) - Empresarial, Tecnológica, Profissional e Comunicativa - e acrescentamos a elas subdimensões a partir do que foi evidenciado pela pesquisa empírica e pela teoria. Na primeira dimensão "Empresarial/Econômica" são 
trabalhados os aspectos que envolvem a gestão econômica de cada jornal, nas seguintes subdimensões e funções organizativas:

1. A empresa: identifica qual o jornalismo priorizado pela empresa de mídia, se o online/digital ou o impresso.

2. Plano de negócio: identifica o perfil de negócios adotado pelo jornal e suas formas de autofinanciamento. Verifica competitividade, preocupação com qualidade, especialização das áreas de cobertura, níveis de inovação.

3. Modelo de negócio: identifica o modelo econômico de negócios adotado pela empresa jornalística (grupo de mídia; companhias; multinacional; etc.)

4. Modelo de redação: identifica o grau de integração do ponto de vista da gestão da redação.

5. Coordenação: verifica a presença/atuação de coordenação a fim de alcançar um objetivo comum.

$\mathrm{Na}$ segunda dimensão, "Tecnológica/Ferramentas" verificamos outras subdimensões:

1. Convergência e integração: identifica o nível de integração ou de convergência adotada pela redação do ponto de vista da produção.

2. Fontes: uso de databases e social networks para coleta de informações.

3. Ferramentas aplicadas: identifica o uso de ferramentas próprias, proprietárias ou livres na rotina jornalística.

4. Tecnologia: identifica os níveis de tecnologia adotados, se há uso de ontologias e semântica.

5. Comunicação: classifica o grau de comunicação interna da redação para troca de ideias ou informações.

Na terceira subdimensão, "Profissional/Jornalista", são abordados aspectos da prática profissional diária que impactam no conteúdo que é produzido:

1. Rotina da redação: identifica as principais rotinas dos fluxos de trabalho.

2. Práticas jornalísticas e métodos de trabalho: identifica as práticas jornalísticas afetadas pelo cenário profissional e quais as principais mudanças verificadas.

3. Canais de distribuição: identifica os canais de distribuição da informação. 
4. Colaboração/Conexão: identifica se os jornais possuem processo de criação compartilhada entre profissionais e público com agregação de habilidades específicas de cada.

Na última dimensão, "Comunicativa/jornal”, checamos as seguintes subdimensões:

1. Ator principal: identificamos a presença ou ausência de um ator principal na redação e qual sua posição.

2. Interação/audiência: identifica como é a participação da audiência na prática profissional e no conteúdo produzido.

3. Situação/posição de mercado: identifica se há e quais são os novos modelos de negócios propostos diante do cenário de integração/convergência.

4. Cooperação: verifica se há acordos internos para alcançar objetivos independentes e coletivos.

As informações acerca de cada uma das dimensões e subdimensões aparecem nos quadros a seguir. 
Quadrro 1 - Empresarial/ Econômica

\begin{tabular}{|c|c|c|c|c|}
\hline A empresa & $\begin{array}{l}\text { Plano de } \\
\text { negócio }\end{array}$ & Modelo de negócio & $\begin{array}{l}\text { Modelo de } \\
\text { redação }\end{array}$ & Coordenação \\
\hline $\begin{array}{c}\text { Impresso é o } \\
\text { carro-chefe } \\
\text { economicamente, } \\
\text { mas há } \\
\text { adequação para } \\
\text { fornecimento } \\
\text { de informação } \\
\text { em todas as } \\
\text { plataformas ao } \\
\text { longo do dia. }\end{array}$ & Grupo de mídia & $\begin{array}{l}\text { O modelo de negócio atual } \\
\text { faz com que o jornal impresso } \\
\text { seja prioritário em função } \\
\text { do retorno financeiro. Com } \\
\text { a concentração dos meios e } \\
\text { suportes profissionais, como } \\
\text { infografia, design, fotografia, } \\
\text { arte e diagramação, busca-se } \\
\text { racionalização e economia. } \\
\text { Há, no entanto, desde } 2017 \text {, } \\
\text { uma aposta clara na virada de } \\
\text { chave com a priorização de } \\
\text { produção e de distribuição de } \\
\text { conteúdos digitais. }\end{array}$ & $\begin{array}{l}\text { Parcialmente } \\
\text { integrada e } \\
\text { convergente até } \\
\text { 2016, quando } \\
\text { avançou para } \\
\text { integração } \\
\text { completa com a } \\
\text { mudança da sede } \\
\text { física em janeiro } \\
\text { de } 2017 .\end{array}$ & $\begin{array}{l}\text { Possui editores } \\
\text { responsáveis por } \\
\text { diferentes áreas } \\
\text { que participam de } \\
\text { reuniões conjuntas } \\
\text { em diferentes } \\
\text { momentos do dia. }\end{array}$ \\
\hline $\begin{array}{l}\text { Impresso é o } \\
\text { carro-chefe da } \\
\text { empresa, embora } \\
\text { mantenha a } \\
\text { cultura do } \\
\text { "digital first". }\end{array}$ & Grupo de mídia & $\begin{array}{l}\text { Adotou a cultura de publicar } \\
\text { primeiro online. Por ter } \\
\text { consciência das mudanças, } \\
\text { investe bastante no jornal } \\
\text { impresso que acredita ser o } \\
\text { diferencial do grupo e que é } \\
\text { responsável por maior receita. } \\
\text { Possui iniciativas para ampliar } \\
\text { a participação do público } \\
\text { na produção de notícias. } \\
\text { Construiu um prédio para } \\
\text { fazer a integração de redações } \\
\text { e está "tropicalizando", ou } \\
\text { seja, fazendo adaptações ao } \\
\text { contexto e à sociedade. Ainda } \\
\text { pairam incertezas e dúvidas } \\
\text { no processo e quanto ao } \\
\text { modelo de negócios. }\end{array}$ & $\begin{array}{l}\text { Integrada e } \\
\text { parcialmente } \\
\text { convergente. }\end{array}$ & $\begin{array}{l}\text { Possui editores } \\
\text { responsáveis por } \\
\text { cada área e que } \\
\text { supervisionam e } \\
\text { revisam conteúdos } \\
\text { antes de irem } \\
\text { ao ar ou serem } \\
\text { publicados no } \\
\text { impresso. }\end{array}$ \\
\hline $\begin{array}{l}\text { Online/multi- } \\
\text { formatos. } \\
\text { Possui tradução } \\
\text { nas versões } \\
\text { internacionais de } \\
\text { seus sites. }\end{array}$ & $\begin{array}{l}\text { A BBC é um } \\
\text { serviço público. } \\
\text { Tem como } \\
\text { orientação: } \\
\text { informar, } \\
\text { educar e } \\
\text { entreter } \\
\text { como uma } \\
\text { organização. } \\
\text { Tem o dever } \\
\text { de abordar } \\
\text { o fenômeno } \\
\text { demográfico } \\
\text { mais amplo. }\end{array}$ & $\begin{array}{c}\text { A absorção de novas } \\
\text { tecnologias não está } \\
\text { necessariamente alinhada } \\
\text { às expectativas de receita. } \\
\text { A Worldwide é o braço } \\
\text { comercial da BBC e traz a } \\
\text { maior parte do seu dinheiro. } \\
\text { A BBC também faz a } \\
\text { distribuição de programas } \\
\text { para outras redes de TV e } \\
\text { possui um escritório que } \\
\text { vende conteúdo para o } \\
\text { Oriente Médio. A maior parte } \\
\text { das receitas anuais totais da } \\
\text { BBC advém das taxas de } \\
\text { licença cobradas no Reino } \\
\text { Unido. Mesmo com cortes, } \\
\text { o Ministério dos Negócios } \\
\text { Estrangeiros sentiu que é } \\
\text { melhor para a BBC ter alguma } \\
\text { presença na China. }\end{array}$ & $\begin{array}{l}\text { Integrada e } \\
\text { parcialmente } \\
\text { convergente. }\end{array}$ & Não verificada. \\
\hline
\end{tabular}

Fonte: elaboração dos autores. 
Quadro 2 - Tecnológica/Ferramentas

\begin{tabular}{|c|c|c|c|c|}
\hline $\begin{array}{c}\text { Convergência e } \\
\text { integração }\end{array}$ & Fontes & $\begin{array}{l}\text { Ferramentas } \\
\text { aplicadas }\end{array}$ & Tecnologia & Comunicação \\
\hline $\begin{array}{l}\text { Integração completa } \\
\text { em 2017. Profis- } \\
\text { sionais do site } \\
\text { resistiram à junção } \\
\text { com o impresso. A } \\
\text { integração melhorou } \\
\text { a interlocução entre } \\
\text { editores e a reda- } \\
\text { ção. Acreditam } \\
\text { que a integração } \\
\text { não é apenas juntar } \\
\text { as redações, mas } \\
\text { "um projeto de } \\
\text { qualificação do } \\
\text { processo de produção } \\
\text { de conteúdo e } \\
\text { distribuição". }\end{array}$ & $\begin{array}{l}\text { Pouco } \\
\text { jornalismo de } \\
\text { dados porque } \\
\text { requer mais } \\
\text { tecnologia. }\end{array}$ & $\begin{array}{c}\text { Ferramenta própria } \\
\text { para gerenciamento de } \\
\text { conteúdo; } \\
\text { Uso do Facebook pelo } \\
\text { celular }\end{array}$ & $\begin{array}{l}\text { Os processos de } \\
\text { atribuição de palavras- } \\
\text { chave. CMS para } \\
\text { produçãa de texto } \\
\text { jornalístico. Usa } \\
\text { ontologias nos sites. Não } \\
\text { houve bom planejamento } \\
\text { de migração para a Web } \\
\text { 3.0. }\end{array}$ & $\begin{array}{l}\text { Premissa de que } \\
\text { deve ser horizontal, } \\
\text { com conversa não- } \\
\text { hierarquizada, em } \\
\text { que alguém de } \\
\text { cima dita alguma } \\
\text { coisa e os abaixo } \\
\text { atendem. Defendem } \\
\text { uma dinâmica mais } \\
\text { equilibrada. }\end{array}$ \\
\hline $\begin{array}{c}\text { Tentativa de } \\
\text { integração e } \\
\text { convergência em } \\
\text { 2007. Resistência } \\
\text { forte devido à } \\
\text { cultura do impresso. } \\
\text { Convergência e } \\
\text { integração avançaram } \\
\text { gradualmente. Fez } \\
\text { a digitalização, } \\
\text { integrou as redações, } \\
\text { mas enfrenta } \\
\text { instabilidades no } \\
\text { desenvolvimento de } \\
\text { novas linguagens. } \\
\text { A fusão total é } \\
\text { planejada, mas carece } \\
\text { de adaptação das } \\
\text { fases anteriores. }\end{array}$ & $\begin{array}{c}\text { Não } \\
\text { identificado. }\end{array}$ & Não identificado. & $\begin{array}{c}\text { Está explorando } \\
\text { maneiras de transformar } \\
\text { seu conteúdo em termos } \\
\text { de linguagem. } \\
\text { Para facilitar o } \\
\text { gerenciamento de } \\
\text { conteúdo em sua página } \\
\text { foi realizado trabalho } \\
\text { para permitir buscas } \\
\text { na web semântica da } \\
\text { plataforma. }\end{array}$ & $\begin{array}{l}\text { Problema de } \\
\text { transparência e de falta } \\
\text { de comunicação, sendo, } \\
\text { às vezes, uma mesma } \\
\text { pauta processada } \\
\text { por dois jornalistas. } \\
\text { Controle de qualidade } \\
\text { do impresso (revisado } \\
\text { por duas a quatro } \\
\text { pessoas). Na web só há } \\
\text { uma pessoa e precisa-se } \\
\text { editar rapidamente. }\end{array}$ \\
\hline $\begin{array}{c}\text { Integrada e com } \\
\text { convergência parcial. } \\
\text { Todas as áreas de } \\
\text { produção estão no } \\
\text { mesmo espaço. } \\
\text { Contudo, o diálogo } \\
\text { fica sob critério ou } \\
\text { demanda de cada } \\
\text { uma. Possui produção } \\
\text { de notícias 24 horas } \\
\text { por dia. Possui } \\
\text { estúdios para muitos } \\
\text { canais e controle } \\
\text { robotizado de } \\
\text { câmeras, com uso de } \\
\text { um documento XML } \\
\text { pré-programado. }\end{array}$ & $\begin{array}{c}\text { BBC } \\
\text { Monitoring, } \\
\text { segue fontes } \\
\text { internacionais. } \\
\text { Jornalistas } \\
\text { usam-no para } \\
\text { identificar as } \\
\text { histórias, mas } \\
\text { fazem muita } \\
\text { filtragem } \\
\text { com esforço } \\
\text { humano. } \\
\text { Equipe } \\
\text { pequena } \\
\text { com alguns } \\
\text { jornalistas de } \\
\text { dados. }\end{array}$ & $\begin{array}{c}\text { Newslab de } \\
\text { tecnologias otimiza } \\
\text { o fluxo de trabalho. } \\
\text { Usam ontologias para } \\
\text { classificar o conteúdo. } \\
\text { Ferramenta própria } \\
\text { de planejamento } \\
\text { (Jportal) de notícias } \\
\text { (não teve sucesso). } \\
\text { Pouco controle } \\
\text { sobre softwares } \\
\text { utilizados. Conseguem } \\
\text { "controlar" o ciclo de } \\
\text { vida de uma tarefa. } \\
\text { Utilizam e-mails } \\
\text { individuais e não } \\
\text { existem padrões } \\
\text { estabelecidos. }\end{array}$ & $\begin{array}{c}\text { Usa tecnologias } \\
\text { semânticas nos sistemas } \\
\text { internos de produção } \\
\text { de conteúdo desde } \\
\text { 2011. Isso permitiu a } \\
\text { publicação de páginas } \\
\text { de agregação de notícias } \\
\text { para as Olimpíadas de } \\
2012 \text { - impossível com } \\
\text { o gerenciamento de } \\
\text { conteúdo curado à mão. } \\
\text { A sustentação semântica } \\
\text { do conteúdo foi lançada } \\
\text { em 2013 para enriquecer } \\
\text { as conexões entre } \\
\text { notícias da BBC News, } \\
\text { ativos de conteúdo, o } \\
\text { site central da BBC e a } \\
\text { World Wide Web. }\end{array}$ & $\begin{array}{c}\text { Na tecnologia, há uma } \\
\text { espécie de abordagem } \\
\text { da Comunidade } \\
\text { de Prática. Cada } \\
\text { área de produto do } \\
\text { departamento de } \\
\text { tecnologia tem uma } \\
\text { liderança técnica. Essa } \\
\text { pessoa atenderia a um } \\
\text { amontoado semanal de } \\
\text { outras pistas técnicas. } \\
\text { É onde rodam histórias } \\
\text { e conversa-se sobre os } \\
\text { trabalhos e problemas. } \\
\text { É descrito como "um } \\
\text { fórum bastante útil } \\
\text { porque é uma espécie } \\
\text { de coisa horizontal". }\end{array}$ \\
\hline
\end{tabular}

Fonte: elaboração dos autores. 


\section{Quadro 3 - Profissional/Jornalista}

Práticas jornalísticas e métodos de trabalho

Mesas de redação integradas, horários flexíveis, sistemas colaborativos. Mesa central sob comando do Globo e do Extra. Divisão em duas áreas: produção de conteúdos, formada por macroeditorias; e publicação, responsável pela edição dos produtos impressos e digitais. Recebe consultoria de grupos internacionais.

Redação dividida: atualidades, entretenimento, economia, desportos, mais os serviços de apoio em infografia, vídeo e foto. Editorias do impresso produzem também para a versão digital. Integração da produção em quatro fases: avaliação de pautas; produção dos conteúdos; avaliação das notícias produzidas; formatação de jornais impressos; e fornecimento de páginas web. O fluxo da redação, denominado "Gestión Editoral de laredación integrada", compreende o planejamento, a produção de conteúdo e a publicação.

Os serviços de $\mathrm{TV}$, rádio, internet e digital da BBC em Londres têm equipes de produção separadas, mas estão lado a lado na sala de redação. Privilegia a produção multimídia para várias plataformas. Cada um sabe seu papel e os profissionais têm liberdade para trabalharem juntos se desejarem. Os avanços identificados na BBC em Londres estão relacionados à percepção de mutações para um ambiente de trabalho mais complexo e colaborativo. A redação está sendo acionada pela introdução de tecnologias e transformações digitais, utilizando ferramentas e frameworks capazes de integrar a Internet com rotinas do processo de produção e uso de semântica.

Mesa central chefiada por um editorexecutivo de integração, com suporte de editores-executivos de produção que atuam para organizar o ciclo de $24 \mathrm{~h}$ dos canais digitais. Primeira reunião editorial às $7: 30 \mathrm{~h}$ para definir os principais temas do dia e os destaques da edição digital, prevendo as atualizações. Especialistas em redes sociais e em audiência participam.

Reunião diária às 9h: um editor digital conta os temas e expõe os não publicados e o porquê. Reunião semanal entre jornalistas e editores de área, com escolha dos temas mais interessantes. Reunião diária com os cinco editores para discutir a agenda da semana (dura, mas flexível) e ver recursos humanos e financeiros necessários. O jornalista leva o tema ao editor. A decisão avança conforme a notícia. Se há muita informação o conteúdo pode ser aprofundado e distribuído para o impresso ou para a web. O conteúdo é "digital first". Ao final do dia se reúnem com editores e escolhem as pautas do impresso. Não discutem estética das publicações na web. Palavras-chaves mais repercutidas na internet são escolhidas pelo Google.
Coleta centralizada e descentralizada de notícias, a critério de cada programa. Informações triadas rapidamente, com fluxo de informações que as leva de forma ágil para o site online do Reino Unido, Site World online (versão vista no Brasil) e World Online geral. A dinâmica das equipes mantém um fluxo estável de trabalho em dias sem grandes novidades/surpresas. Em dias com novidades a estrutura se desfaz e tornam-se comuns grandes e frenéticas discussões.

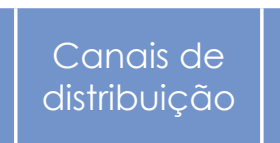

Colaboração/

Conexão

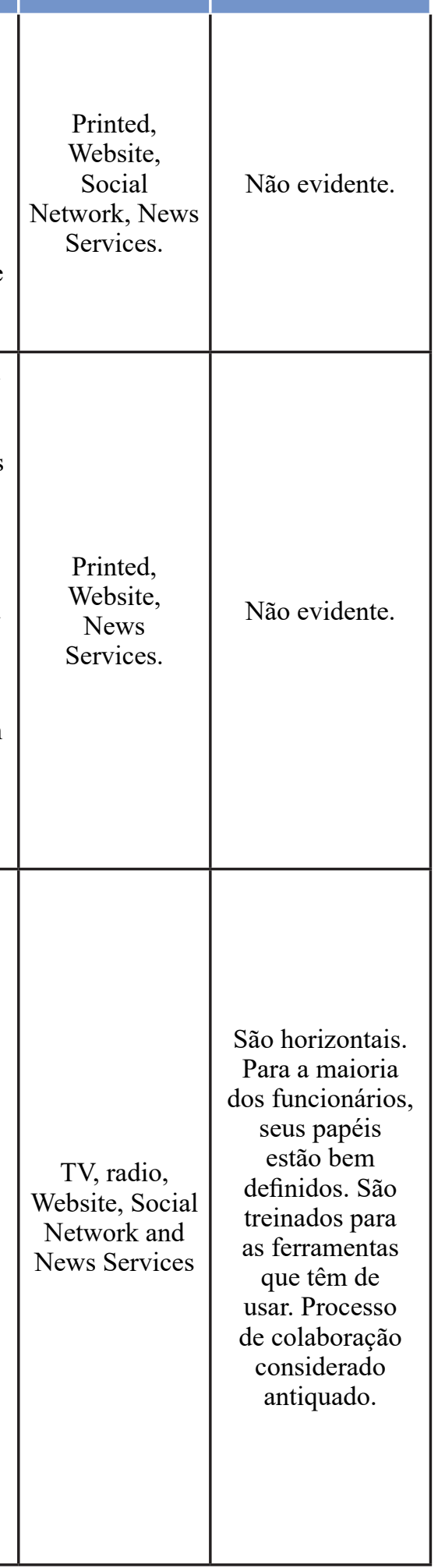

Fonte: elaboração dos autores. 
Quadro 4 - Comunicativa/Jornal

\begin{tabular}{|c|c|c|c|c|}
\hline & Ator principal & Interação/Audiência & $\begin{array}{l}\text { Situação/ } \\
\text { posição de } \\
\text { mercado }\end{array}$ & Cooperação \\
\hline & $\begin{array}{l}\text { Editor para abrir e } \\
\text { fechar as edições. }\end{array}$ & Não evidente. & $\begin{array}{c}\text { Diminuição } \\
\text { no número de } \\
\text { jornalistas (de } 500 \\
\text { para } 400)\end{array}$ & Não evidente. \\
\hline & $\begin{array}{c}\text { Editores para cada } \\
\text { área. }\end{array}$ & Não evidente. & Não evidente. & $\begin{array}{l}\text { Falta integrar mais } \\
\text { a equipe de apoio, } \\
\text { "nos falta fortalecer } \\
\text { um pouco mais a } \\
\text { integração proativa da } \\
\text { equipe de apoio, porque } \\
\text { hoje o infografista, } \\
\text { o desenhista e os } \\
\text { fotógrafos participam } \\
\text { das reuniões mas não } \\
\text { dão ideias, não dão } \\
\text { aportes: não dizem nada. } \\
\text { "Falta que eles aportem } \\
\text { e enriqueçam a oferta da } \\
\text { gama de conteúdos". }\end{array}$ \\
\hline & $\begin{array}{l}\text { Há um editor para } \\
\text { redes sociais. } \\
\text { Há um editor para o } \\
\text { site, mas não há um } \\
\text { editor para um tipo } \\
\text { específico de saída. }\end{array}$ & $\begin{array}{l}\text { A publicação de } 455.465 \\
\text { páginas de artistas dentro } \\
\text { da BBC.co.uk é muito } \\
\text { mais do que a equipe } \\
\text { atual da empresa pública } \\
\text { poderia publicar sozinha. } \\
\text { A estratégia deixou os } \\
\text { jornalistas livres para } \\
\text { escreverem em casa e } \\
\text { também conta com a } \\
\text { participação do público } \\
\text { na produção. }\end{array}$ & $\begin{array}{c}\text { O departamento da } \\
\text { BBC Future Media } \\
\text { está usando para } \\
\text { evoluir a partir } \\
\text { de um modelo de } \\
\text { conteúdo relacional } \\
\text { e estrutura de } \\
\text { publicação estática } \\
\text { para uma arquitetura } \\
\text { de publicação } \\
\text { semântica } \\
\text { totalmente dinâmica } \\
\text { (DSP). }\end{array}$ & $\begin{array}{l}\text { O compartilhamento } \\
\text { de conhecimento é um } \\
\text { problema. A troca de } \\
\text { informações se dá pelas } \\
\text { relações pessoais, como } \\
\text { na hora do café, por } \\
\text { exemplo. } \\
\text { Possuem uma intranet } \\
\text { que tenta organizar } \\
\text { informações. Há cursos } \\
\text { de vídeo online ou } \\
\text { cursos presenciais aos } \\
\text { quais os profissionais } \\
\text { podem comparecer. } \\
\text { Entretanto, atuam muito } \\
\text { individualmente e por } \\
\text { isso recebem treinamento } \\
\text { específico para suas áreas } \\
\text { de atuação. }\end{array}$ \\
\hline
\end{tabular}

Fonte: elaboração dos autores.

\section{O estágio de convergência das redações}

Em busca de adaptação ao cenário digital, a convergência é inevitável - alertavam Salaverría e Negredo (2008) já na primeira década dos anos 2000. Desde então, a velocidade 
das transformações nas redações jornalísticas ficou ainda mais intensa. E, hoje, jornais não podem abrir mão de estar de forma expressiva e eficiente na plataforma online, onde se evidenciam as empresas de mídia nativas digitais (hoje concorrentes diretas, tanto na busca de público como de verbas publicitárias).

Entre as três empresas visitadas, a redação da BBC Television é a que, na época da pesquisa de campo, encontrava-se em estado mais avançado neste sentido, com iniciativas concretas de organização da estrutura e do pessoal para a priorização de produção, edição e distribuição de conteúdo digital nas plataformas online. Por não enfrentar a dicotomia entre impresso e digital, o fluxo do processo pode ter sido facilitado.

Em menor grau, O Globo e La Nación também apresentavam avanços, mas ainda com uma evidente supremacia da versão impressa. No caso de O Globo, é preciso reconhecer que tal situação começou a se transformar de forma mais enfática em janeiro de 2017, um ano após a visita, quando a empresa mudou de sede física e reorganizou a estrutura de produção e distribuição com foco no conteúdo online ${ }^{17}$, tendo inclusive lançado uma série de novos produtos logo em seguida ${ }^{18}$. Mas ainda assim, mesmo com a aposta no digital aparecendo de forma acentuada, a versão em papel continuava sendo a principal fonte de recursos financeiros e ainda ganhando forte atenção da empresa. Os conteúdos originais (jornal impresso, telejornais e programas de rádio) continuam existindo em suas versões clássicas e, assim, devem seguir por tempo indeterminado. Entretanto, faz-se importante reconhecer que o conteúdo que vai ser publicado na plataforma digital terá mais chances de chegar até as novas gerações de leitores que estão sendo formadas no contexto atual de sociedade conectada.

Como dito no início deste trabalho, Salaverría e Negredo (2008) também afirmavam que a integração das redações é um dos caminhos para a convergência, mas não o único. Pesquisas recentes têm comprovado isso na prática (GARCÍA e FARIÑA, 2010, Áviles et al., 2014; Deuze, 2011 e 2018; Lenzi, 2018). Após estudo recente envolvendo os jornais espanhóis El País e El Mundo, o norte-americano The New York Times, o argentino Clarín e os brasileiros Folha de S. Paulo, Gazeta do Povo, O Estado de S. Paulo, O Globo e Zero Hora, Lenzi aponta que "a tendência contemporânea das redações é de uma captação integrada, com apuração e redação conjunta; e de uma edição "desintegrada", com núcleos separados para que cada plataforma tenha seu empacotamento" (Lenzi,

\footnotetext{
${ }^{17}$ O Globo, Extra e Expresso se integram em uma redação multimídia. Disponível em: <http://oglobo.globo.com/brasil/o-globo-extra-expresso-se-integram-em-uma-redacao-multimidia-20840004>. Acesso em: 29 jan. 2017.

${ }^{18}$ O Globo lança novos produtos digitais. Disponível em: <http://oglobo.globo.com/brasil/o-globo-lancanovos-produtos-digitais-21048657>. Acesso em: 12 mar. 2017.
} 
2018, p. 281). No entanto, os processos de transição para a integração e a convergência não foram processos aceitos de forma unânime pelos profissionais, havendo inicialmente resistência por parte das equipes de impresso a unirem-se às do digital - caso relatado em O Globo e La Nación. Isso especialmente porque o digital era tido como de menor qualidade e glamour em relação ao impresso. Na BBC as mesas são integradas, mas os processos produtivos podem ocorrer separadamente, de acordo com o interesse dos profissionais.

Com a integração feita e a convergência em processo de incorporação, tornam-se visíveis as alterações nos fluxos de trabalho. Em relação à comunicação e à colaboração, têmse diferentes estágios. Em O Globo, a premissa é seguir uma hierarquização mais dinâmica e horizontal, embora não seja uma regra, com colaboração a critério dos profissionais. Já no La Nación relatam-se problemas de transparência e de falta de comunicação. Por último, na BBC, a comunicação ou troca de informações entre os profissionais não é obrigatória, mas uma iniciativa pessoal, o que se tornou um problema devido ao não compartilhamento de informações. Ainda assim, os processos de negociação passaram a envolver profissionais da redação (jornalistas, designers, etc.), editores-executivos e também os proprietários.

No fluxo de produção, a presença de tecnoatores, um dos pilares que caracterizam a mudança trazida pelo processo de convergência, ganhou força, embora a participação destes em relação ao conteúdo ainda seja tímida. As realidades expostas pelas entrevistas demonstram que esses profissionais desempenham papéis fundamentais na convergência do trabalho, com profissionais não jornalistas atuando diretamente com o jornalismo convergente.

Apesar da integração total das redações e das iniciativas de convergência, o fluxo de trabalho das três redações segue o padrão tradicional do jornalismo com reunião de pauta pela manhã, produção, revisão, publicação online, reunião de fechamento e publicação impressa. As etapas não são estanques e podem ser derrubadas e/ou alteradas, caso necessário. Porém, no cenário padrão, mantêm-se dessa forma. O conteúdo jornalístico passou a contar com a incorporação de novos elementos, como o uso de web semântica, tags, palavras-chave e outros elementos que permitem ao texto ser facilmente encontrado no universo web. Esses elementos são os que mais mexem com a capacidade de produção dos jornalistas.

Exemplo prático do discurso acima é demonstrado neste estudo, evidenciando que $\mathrm{O}$ Globo, La Nación e BBC Television trabalham no contexto de convergência 
experimentando transformações de rotina com foco em atrair e manter um público que consome conteúdo preferencialmente nas plataformas digitais. Embora em diferentes níveis de intensidade, tal iniciativa ocorre de maneira concreta nas três redações, um indicativo claro de que, mesmo ainda sendo difícil especificar claramente o caminho a ser seguido, há cada vez mais um considerável consenso de que a nova rota conduz ao digital.

\section{O modelo explicativo multinível de convergência}

$\mathrm{Na}$ "Figura 1" propomos um modelo explicativo multinível de convergência com base nas relações entre as quatro dimensões nas três redações analisadas.

Figura 1 - Mapa mental do modelo explicativo multinível de convergência

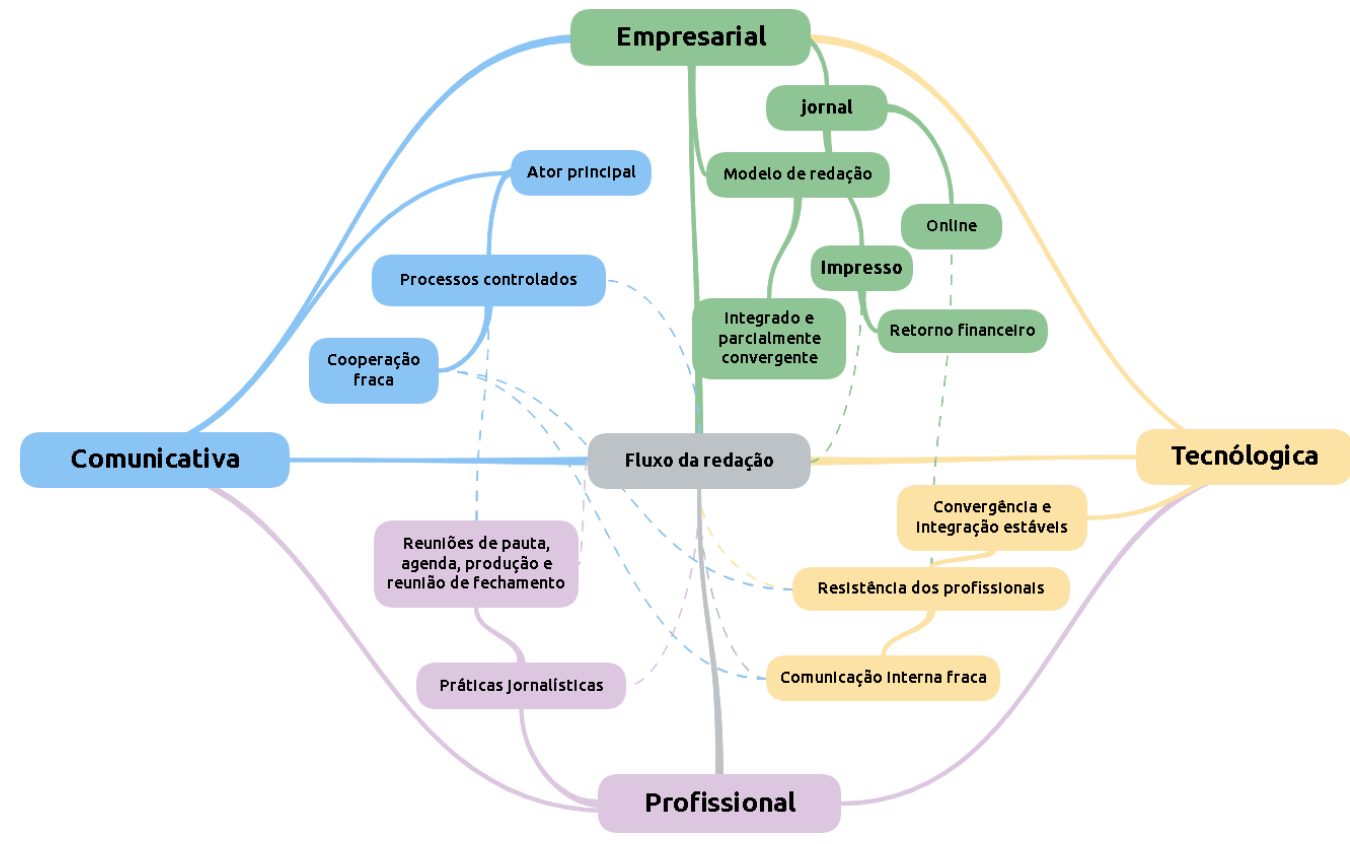

Fonte: elaboração dos autores.

A rotina da redação desempenha papel central nesse modelo, pois afeta e é afetada por diversos processos. Ainda que esteja dentro da dimensão empresarial, por ser este o suporte principal da existência dos jornais/redações, seu papel sobressai pelas inúmeras relações que desencadeia com as outras três dimensões. Assim, consideramos:

1. A dimensão empresarial ainda é o suporte principal do ciclo jornalístico. Ela é responsável por dois grandes eixos: o modelo de redação e o jornal. O modelo 
de sala de redação mostra-se integrado e parcialmente convergente. Já o jornal ramifica-se em dois nichos, o impresso e o online (exceto BBC TV que é apenas online), que recebem diferentes valorações em termos de capital social e publicações. O impresso continua sendo a fonte de renda principal dos jornais que atuam nos dois nichos. Esses dois eixos interferem na rotina da redação, pois exige-se uma logística de produção que permita conteúdos diferentes nas duas mídias. Contudo o online permanece o mais afetado pela resistência dos profissionais.

2. A mudança no fluxo de trabalho da redação, devido à integração e à convergência parcial, é também influenciada por elementos das dimensões jornal, tecnologia e profissional. O fluxo de trabalho da redação ainda aparece como dorsal nas empresas jornalísticas e os impactos das mudanças recaem diretamente sobre ele, com processos de controle que se iniciam no ator principal, perpassam as reuniões de pauta - diárias; e as etapas de pré-publicação (escrita, checagem, e revisão). O desafio da rotina da redação encontra-se em romper a resistência dos profissionais às etapas dos processos e à interação com seus pares.

3. Embora o processo de convergência e de integração possa ser considerado estável, olhando-se pelo aspecto tecnológico, ainda existe resistência dos profissionais a esse processo de mudança, o que provoca também uma comunicação ineficiente entre as equipes, afetando diretamente a dimensão comunicativa/jornal. Dentro desta dimensão, todas as redações possuem ainda um ator principal, geralmente na função de editor, e os processos internos são controlados por eles ou pelos responsáveis das áreas. Ainda que haja um centralizador que poderia mediar a comunicação, nesta dimensão todos os jornais relatam uma cooperação fraca, que se interliga à resistência dos profissionais, identificada na dimensão da tecnologia. Asssim, fica a critério de cada profissional descobrir ferramentas e produzir conteúdo - sem a imposição de pensar a convergência com o conteúdo produzido pelos colegas.

4. Na dimensão que trata do profissional, evidencia-se que as práticas jornalísticas mantiveram um fluxo mínimo que envolve reunião de pauta, produção, publicação e fechamento. Essas etapas podem variar em intensidade e inclusive em sua ordem, uma vez que o online não possui um "fechamento" como o impresso, mas um processo de atualização constante, o que exige um 
planejamento contínuo, característico de processos integrados e convergentes. Esse processo é mantido em funcionamento

A partir disso, pode-se argumentar que a convergência, a coexistência e a divergência nas redações são os três processos que caracterizam a evolução das mídias nos jornais. No entanto, a convergência é seguramente a mais presente nos projetos de integração ou de reestruturação das instalações das empresas - e também entre os temas dos trabalhos de investigação na academia. Como a maioria dos departamentos de marketing dos jornais têm usado o termo convergência para rotular qualquer movimentação de organização nos fluxos de informação (rotinas), na alocação dos jornalista e dos profissionais nas equipes para produção das matérias jornalísticas e na forma como os conteúdos são elaborados para diversos canais ou multiplataformas de distribuição, optou-se por definir convergência e suas relações no início deste texto, buscando evitar entendimentos equivocados.

O segundo ponto tem a ver com a inquestionável transformação digital que passam todas organizações, e logo gestores são permanentemente cobrados para apresentarem novos modelos gerenciais e organizacionais, pois consideram que os atuais modelos em vigor não conseguem responder aos desafios do mercado. E justificam que as práticas organizacionais dentro das redações e nas relações com os clientes, com as empresas de comunicação e com seus consumidores não são suficientemente flexíveis. E, portanto, não são apropriadas para a realidade em que as empresas de mídia atualmente operam.

Em termos de estudos futuros, reforçamos a necessidade de mais pesquisas nas diversas direções, notadamente nas quatro dimensões que são a base do modelo comparativo de convergência proposto aqui, uma vez que ao se concentrar apenas em uma dimensão ou subdimensão corre-se o risco de perder ou prejudicar o entendimento e/ou concepção do todo. Finalmente, uma discussão geral da aplicação do modelo levará a novas pesquisas. E pode levantar questões que permitam abrir o horizonte para futuros estudos no campo.

\section{Referências}

AVILÉS, José A. García. Desmitificando la convergencia periodística. Revista Latinoamericana de Comunicación Chasqui. Quito: Equador, n. 94, 2006, p. 34-39. 
AVILÉS, José A. García; CARVAJAL, Miguel; KALTENBRUNNER, Andy; KRAUS, Daniela; e MEIER, Klaus. Newsroom integration in Austria, Spain and Germany: models of media convergence. Journalism Practice, Inglaterra: Londres, n. 3, 2009, p. 285-303.

AVILÉS, José Alberto García; KALTENBRUNNER, Andy; e MEIER, Klaus. Media convergence revisited: lessons learned on newsroom integration in Austria, Germany and Spain. Journalism Practice. Inglaterra: Londres, n. 8, 2014, p. 573-584.

BELOCHIO, Vivian. Jornalismo em contexto de convergência: implicações da distribuição multiplataforma na ampliação dos contratos de comunicação dos dispositivos de Zero Hora. 2012. Tese (Doutorado em Comunicação e Informação), Universidade Federal do Rio Grande do Sul (UFRGS),2012.

DEUZE, Mark (Org.). Managing media work. Califórnia (EUA): Sage, 2011.

DEUZE, Mark; WITSCHGE, Tamara. Beyond journalism: theorizing the transformation of journalism. Journalism. Inglaterra: Londres, Online First, 2017, p. 1-17. Disponível em: $<$ https:// goo.gl/hEjh1R>. Acesso em 10 fev. 2017.

DEUZE, Mark; PRENGER, Miriam (Org.) Making media: production, practices and professions. Holanda: Amsterdam University Press, 2018.

FARIÑA, Xosé Pereira; GARCÍA, Xosé López (Coord.). Convergencia digital: reconfiguración de los medios de comunicación en España. Espanha: Universidade de Santiago de Compostela, 2010.

HANITZSCH, Thomas. Deconstructing Journalism Culture: Toward a Universal Theory. Comunicação Theory, 2007, p. 260-380.

JENKINS, Henry. Cultura da convergência. 2a edição. São Paulo: Aleph, 2009.

JORGE, Thaïs de Mendonça. A notícia em mutação: estudo sobre o relato noticioso no jornalismo digital. 2007.

LENZI, Alexandre. Inversão de papel: prioridade ao digital, um novo ciclo de inovação para jornais impressos. Florianópolis: Insular, 2018. 
MENKE, Manuel; KINNEBROCK, Susanne; KRETZSCHMAR, Sonja; AICHBERGER, Ingrid; BROERSMA, Marcel; HUMMEL, Roman; KIRCHHOFF, Susanne; PRANDNER, Dimitri; RIBEIRO, Nelson; SALAVERRÍA, Ramón. Convergence culture in European newsrooms: comparing editorial strategies for cross-media news production in six countries. Journalism Studies, Londres: Routledge, p. 1-24, 2016.

SALAVERRÍA, Ramón. Convergencia de los medios. Revista Latinoamericana de Comunicación Chasqui. Equador: Quito, n. 81, 2003, p. 33-39.

SALAVERRÍA, Ramón; NEGREDO, Samuel. Periodismo integrado: convergencia de medios y reorganización de redacciones. Barcelona, 2008.

SALAVERRÍA, Ramón. Multimedialidade: informar para cinco sentidos. In: CANAVILHAS, João (Org.). Webjornalismo: 7 caraterísticas que marcam a diferença. Portugal: Covilhã. LabCom, 2014, p. 25-52.

TÁRCIA, Lorena Peret Teixeira. Ação, pesquisa e reflexão sobre a docência na formação do jornalista em tempos de convergência das mídias digitais, 2007. Dissertação (Mestrado em Educação), PUC/ Minas Gerais, 2007.

${ }^{1}$ Doutoranda pelo Programa de Pós-Graduação em Comunicação e Sociedade da Univer-sidade de Brasília, com sanduíche pela Brunel University, em Londres, Reino Unido. Professora substituta na Faculdade de Comunicação da Universidade de Brasília. Mem-bro do grupo de pesquisa Ciência Tecnologia e Política (CTPOL) e do Núcleo de Estu-dos em Mídia e Política (NEMP). E-mail: ebidasantos@gmail. com.

${ }^{2}$ Doutor em Jornalismo pela Universidade Federal de Santa Catarina (UFSC), com pes-quisa sobre as transformações das redações jornalísticas convergentes, tendo participado como pesquisador visitante do Center for Internet Studies and Digital Life, da Univer-sidade de Navarra, Espanha, sob orientação do professor Dr. Ramón Salaverría, em ou-tubro e novembro de 2016. Autor do livro Inversão de papel: prioridade ao digital, um novo ciclo de inovação para jornais impressos, publicado em 2018 pela Editora Insular. Professor de Jornalismo na Unisul. E-mail: lenzi.alexandre@gmail.com

${ }^{3}$ Professor Visitante no Computer Science Department, Brunel University, Londres, Rei-no Unido, em 2018. Pesquisador e Professor da Faculdade de Comunicação (FAC), do Departamento de Ciência da Computação (CIC) e do Instituto de Exatas (IE) na Uni-versidade ed Brasília. Pesquisador Associado da Escola do Futuro-USP. Pós-Doutorado em FrameWork Semântico para Jornalismo em 2018 pela FAC/CIC/ IE da Universidade de Brasília e em Literacy digital e mobile learning pela Escola de Comunicação e Arte da Universidade de São Paulo (USP), em 2014. E-mail: beneditomedeirosne-to@gmail.com

${ }^{4}$ Professor de Ciências da Computação no Department of Computer Science da Brunel University, Londres, Reino Unido. Realiza pesquisas dentro do pesquisa dentro do flu-xo de computação visual e multimídia do Centro de Análise Inteligente de Dados (CI-DA). Atividades de pesquisa estão na confluência de Ciência da Computação, Mídia e Psicologia. Em particular, o trabalho se concentra na área de qualidade de multimídia perceptiva e como se constroem sistemas de comunicação de ponta a ponta, incorporando requisitos de percepção do usuário.Co-editor dos livros: Digital Multimedia Percep-tion and Design e Múltiplos Sensory Media Advances and Applications: Novos Desen-volvimentos em Mulsemedia. E-mail: george.ghinea@gmail.com. 